\title{
PENGEMBANGAN BRIKET BERBAHAN DASAR ECENG GONDOK DAN ABU SEKAM PADI SEBAGAI ALTERNATIF BAHAN BAKAR OVEN TEMBAKAU
}

\author{
Sukainil Ahzan'), Dwi Pangga1), Dwi Sabda Budi Prasetya'), A'an Hardiyansyah Putra Wijaya1) \\ 1)Program Studi Pendidikan Fisika, Fakultas Sains, Teknik dan Terapan, Universitas Pendidikan Mandalika, Mataram, \\ NTB, Indonesia \\ Corresponding author: Dwi Pangga \\ E-mail : sukainil Ahzan@ikipmataram.ac.id
}

Diterima 24 November 2020, Direvisi 15 April 2021, Disetujui 16 April 2021

\begin{abstract}
ABSTRAK
Tujuan dari penelitian ini yaitu untuk menghasilkan briket sebagai bahan bakar alternatif oven tembakau. Briket yang dihasilkan ada dua yaitu briket berbahan Dasar Eceng Gondok dan Briket berbahan dasar abu sekam padi. Kedua briket dibuat dengan variasi komposisi bahan perekat tepung tapioka $10 \%$ dan bahan dasar $90 \%$ untuk mendapatkan hasil briket terbaik untuk diterapakan sebagai alternatif bahan bakar pada proses pengovenan tembakau masyarakat.Selain variasi bahan dasar dilakukan juga variasi pada geometri pelet yang meliputi kotak pejal, kotak berongga, tabung pejal, dan tabung berongga. Masing-masing geometri dicetak dengan variasi tekanan 10 PSI, 20 PSI, dan 30 PSI. Hasil penelitian menunjukkan bahwa briket dengan bahan dasar abu sekam padi menghasilkan kalor yang lebih tinggi dibandingkan dengan briket berbahan dasar eceng gondok. Geometri pelet briket berongga menghasilkan kalor yang lebih tinggi dibandingkan dengan briket pejal. Geometri kotak berongga mengasilkan kalor terbaik dibandingan dengan geometri tabung pejal. Tekanan optimum dalam pembuatan pelet briket dihasilkan pada tekanan $20 \mathrm{PSI}$.
\end{abstract}

Kata kunci: briket; eceng gondok; abu sekam padi; oven tembakau.

\begin{abstract}
The purpose of this research is to produce briquettes as an alternative fuel for tobacco ovens. There are two briquettes produced, namely briquettes made from water hyacinth and briquettes made from rice husk ash. The two briquettes were made with a variation of the composition of $10 \%$ tapioca starch adhesive and $90 \%$ base material to get the best briquette results to be applied as an alternative material in the community tobacco oven process. In addition to variations in the basic material, variations in pellet geometry were also carried out, which included solid boxes, hollow boxes, solid tubes, and hollow tubes. Each geometry is printed with a pressure variation of $10 \mathrm{PSI}, 20 \mathrm{PSI}$, and $30 \mathrm{PSI}$. The results showed that briquettes made from rice husk ash produced higher heat than water hyacinth briquettes. Hollow briquette pellet geometry produces higher heat compared to solid briquettes. Hollow box geometry produces the best heat compared to solid tube geometry. The optimum pressure in the manufacture of briquette pellets is produced at a pressure of $20 \mathrm{PSI}$.
\end{abstract}

Keywords: briquettes; water hyacinth; rice husk ash; tobacco oven.

\section{PENDAHULUAN}

Tingginya persentase jumlah petani yang menanam tembakau di Nusa Tenggara Barat cukup mendongkrak perekonomian masyarakat. Namun di sisi lain menyebabkan semakin menipisnya pepohonan karena banyak ditebang untuk dijadikan bahan bakar oven tembakau (Pangga \& Ahzan, 2019). Berbagai solusi telah dilakukan oleh para ilmuan untuk mengatasi ketergantungan terhadap sumber energi tak terbarukan. Diantara berbagai solusi tersebut adalah dengan memanfaatkan energi terbarukan seperti biomassa. Energi biomassa dengan metode pembriketan adalah mengkonversi bahan baku padat menjadi suatu bentuk hasil kompaksi yang lebih mudah untuk digunakan (Sulistyaningkarti \& Utami, 2017).

Penggunaan biobriket sebagai bahan bakar merupakan salah satu solusi alternatif untuk menghemat pemakaian bahan bakar fosil. Penggunaan secara berkelanjutan dapat mengurangi dampak emisi karbon (Supatata et al., 2013). Bahan dasar alternative yang dapat digunakan untuk membuat briket adalah bahan biomassa. Bahan biomassa yang dapat digunakan di daerah Lombok adalah eceng gondok dan abu sekam padi.

Eceng gondok (Eichhornia crassipes) adalah salah satu jenis tumbuhan air yang 
mengapung. Eceng gondok memiliki kecepatan tumbuh yang tinggi sehingga tumbuhan ini dianggap sebagai gulma yang merusak lingkungan perairan (Ariyanto et al., 2014). Eceng gondok sangat banyak ditemukan di perairan, baik di sungai, waduk, maupun di bendungan. Bahkan di bendungan Batujai, pertumbuhan eceng gondok yang begitu cepat, menjadi permasalahan pemerintah yang tidak kunjung selesai dari tahun ketahun (Lalu Muhammad Alfian R, Sukainil Ahzan, 2020). Selain pertumbuhannya yang sangat cepat, keberadaan yang sangat melimpah, serta ketermanfaatannya yang belum maksimal perlu dicarikan solusinya. Pertumbuhan eceng gondok yang cepat terutama disebabkan oleh air yang mengandung nutrien yang tinggi, terutama yang kaya akan nitrogen, fosfat dan potassium (Ariyanto et al., 2014). Bahkan populasi eceng gondok dapat menjadi dua kali lipat sedikitnya dalam waktu enam hari (Nurlela, 2015).

Eceng gondok cocok dijadikan bahan briket (Pangga \& Ahzan, 2019) karena mengandung banyak unsur karbon terutama selulosa $\left(\mathrm{C}_{6} \mathrm{H}_{10} \mathrm{O}_{5}\right)$ dan banyak unsur lainnya seperti yang tertera pada Tabel 1 .

Tabel 1. Kandungan kimia eceng gondok

\begin{tabular}{lc}
\multicolumn{2}{c}{ segar } \\
\hline \multicolumn{1}{c}{ Senyawa kimia } & Persentase (\%) \\
\hline Air & 92,6 \\
\hline Abu & 0,44 \\
\hline Serat kasar & 2,09 \\
\hline Karbohidrat & 0,17 \\
\hline Lemak & 0,35 \\
\hline Protein & 0,16 \\
\hline Fosfor sebagai & 0,52 \\
P2O5 & \\
\hline Kalium sebagai K2O & 0,42 \\
\hline Klorida & 0,26 \\
\hline Alkanoid & 2,22 \\
\hline \multicolumn{2}{r}{ Sumber : (Supatata et al., 2013$)$}
\end{tabular}

Bahan biomassa yang kedua adalah Sekam padi. Sekam padi merupakan lapisan keras yang meliputi kariopsis yang terdiri dari dua belahan yang disebut lemma dan palea yang saling bertautan. Pada proses penggilingan beras, sekam bahan terpisah dari butir beras dan menjadi bahan sisa atau limbah penggilingan, sekam padi dikategorikan sebagai biomassa yang dapat digunakan untuk berbagai kebutuhan seperti bahan baku industry, pakan ternak dan energy atau bahan bakar. Dari proses penggilingan padi biasanya diperoleh sekam sekitar 20-30\%, dedak antar 8$12 \%$ dan beras giling antara $50-63,5 \%$ data bobot awal gabah. Penelitian briket dari (Jamilatun, 2012) dengan bahan biomassa sekam padi menghasilkan nilai kalor cukup inggi yaitu sebesar $3.073 \mathrm{kal} / \mathrm{gr}$ dengan nyala api yang besar dan relatif mudah dinyalakan. Menurut (Patabang, 2012) briket dengan abu sekam padi dengan perekat $7 \%$ memiliki potensi energi biomassa sebesar 11.902 GJoule.

Kualitas pembentukan briket sangat dipengaruhi dari geometri pellet, tekanan briket, jenis perekat dan nilai kadar air bahan (Aljarwi et al., 2020). Geometri pelet adalah bentuk dari sebuah pelet, bisa berupa kubus, balok dan silinder. Menurut (Asri \& Indrawati, 2018) briket dengan bentuk silinder memiliki karakteristik lebih mudah menyala daripada briket berbentuk kotak karena jika ditata sejajar briket bentuk silinder memiliki ruang lebih banyak untuk oksigen.

Berdasarkan latar belakang di atas penelitian ini bertujuan membuat briket dari bahan eceng gondok dan abu sekam padi dengan 2 bentuk geometri yang berbeda yaitu kotak dan tabung serta variasi tekanan. Kualitas briket diukur dengan menganalis nilai kalor yang dihasilkan.

\section{METODE PENELITIAN}

Jenis penelitian ini adalah penelitian eksperimental/penelitian murni di laboratorium. Dalam penelitian digunakan komposisi dengan 90\% Arang Eceng Gondok + 10\% Perekat. Demikian juga untuk briket sekam padi menggunakan komposisi $90 \%$ arang sekam padi dan $10 \%$ perekat. Diagram alir penelitian untuk briket eceng gondok dan briket abu sekam padi seperti terlihat pada Gambar 1.

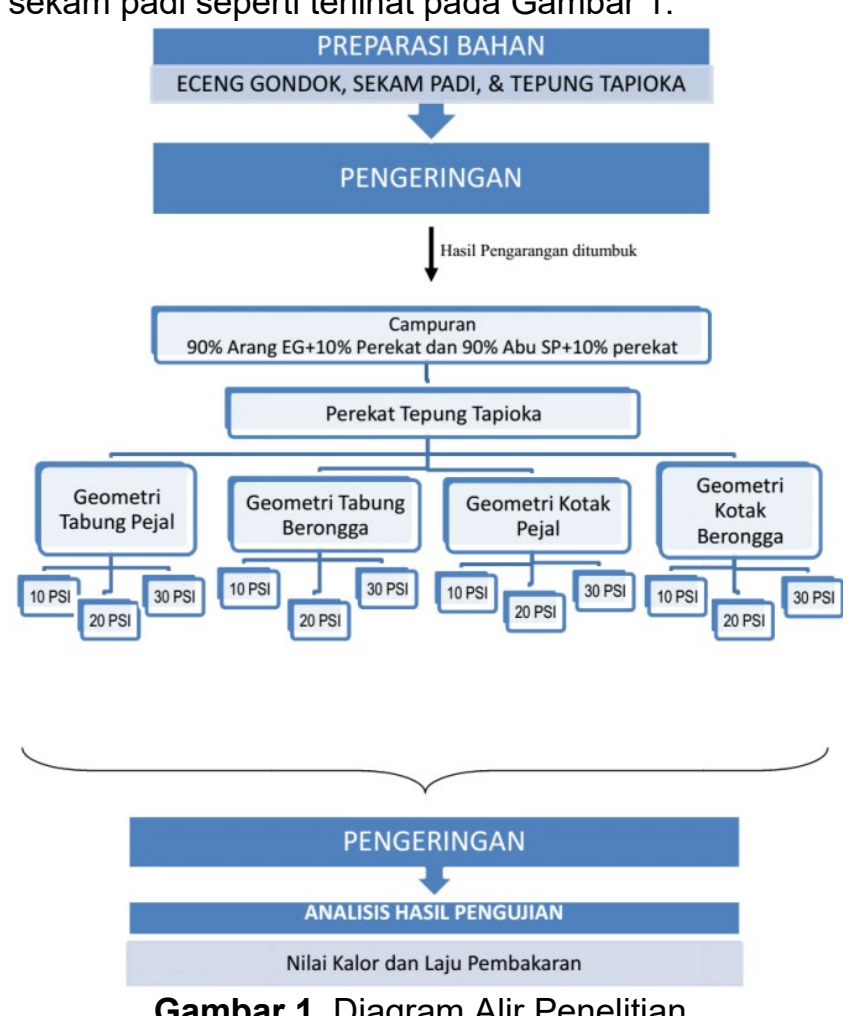

Gambar 1. Diagram Alir Penelitian 
Briket dibuat dari kedua bahan, masing-masing dibuat dengan bentuk geometri tabung pejal, tabung berongga, kotak pejal dan kotak berongga. Masing masing briket dengan geomteri yang berbeda dikempa dengan 3 jenis tekanan, yaitu $10 \mathrm{PSI}, 20 \mathrm{PSI}$ dan $30 \mathrm{PSI}$. Semua hasil briket kemudian dianalisis nilai kalornya. Nilai kalor dapat diperoleh secara manual dengan mengukur perubahan suhu pada air ketika dipanaskan dengan sampel briket, kemudian dihitung dengan persamaan:

$$
\begin{array}{r}
\text { Nilai kalor }(\mathrm{Q})=m c \Delta T \ldots \ldots \ldots(1) \\
\text { Keterangan: } \mathrm{m}=\text { massa air }(\mathrm{Kg}) \\
\mathrm{c}=\text { massa jenis air }\left(\mathrm{kg} / \mathrm{m}^{3}\right) \\
\Delta T=\text { Perubahan suhu }\left({ }^{\circ} \mathrm{K}\right)
\end{array}
$$

\section{HASIL DAN PEMBAHASAN}

Pembuatan briket dilakukan dengan menggunakan dua bahan dasar yaitu arang eceng Gondok dan Abu sekam padi. Penggunaan dua bahan tersebut dimaksudkan untuk mengetahui bahan dasar apa yang paling cocok digunakan sebagai alternatif bahan bakar pada pengovenan tembakau. Untuk mendapatkan hasil yang lebih maksimal, dilakukan juga variasi geometri dan tekanan pada saat pembentukan/percetakan pelet. Variasi geometri meliputi bentuk kotak, kotak berongga, tabung, dan tabung berongga. Sedangkan variasi tekanan pembentukan meliputi bentuk tekanan $10 \mathrm{PSI}, 20 \mathrm{PSI}$, dan 30 PSI.

Adapun bentuk briket dan data yang dihasilkan seperti terlihat pada gambar dan tabel di bawah ini.

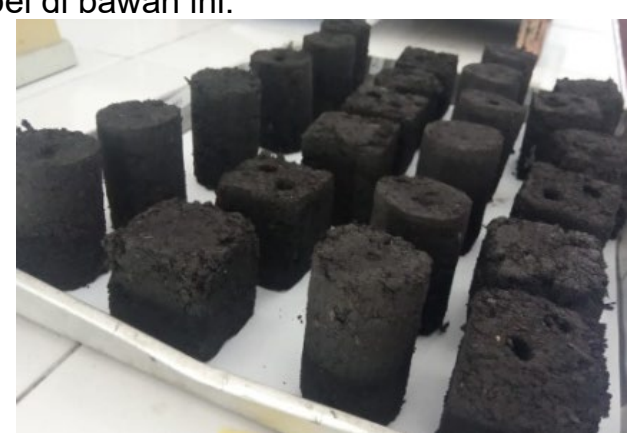

Gambar 2.Briket Eceng Gondok

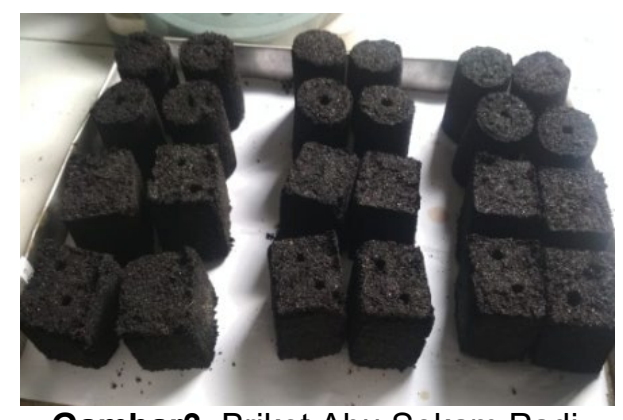

Gambar3. Briket Abu Sekam Padi

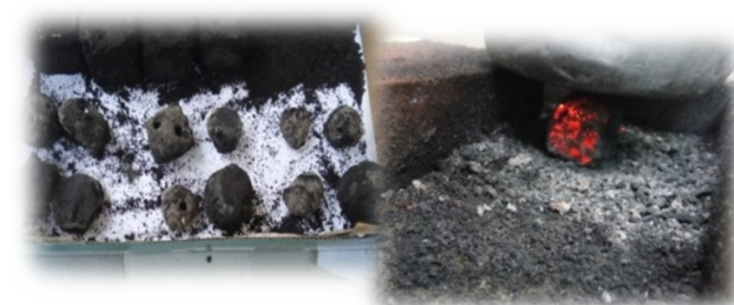

Gambar 4. Proses Pembakaran briket hingga mencapai suhu maksimum

Hasil penelitian penelitian pada Tabel 2 dan 3 terlihat bahwa terdapat hubungan yang sangat signifikan antara bahan dasar, geometri, dan tekanan pembentukan pellet-peletBriket dengan bentuk silinder memiliki karakteristik lebih mudah menyala daripada briket berbentuk kotak karena jika ditata sejajar briket bentuk silinder memiliki ruang lebih banyak untuk oksigen (Asri \& Indrawati, 2018).Laju pembakaran briket menjadi lebih tinggi pada kecepatan aliran udara yang lebih tinggi. Kecepatan udara yang lebih besar memberikan supply oksigen yang lebih besar juga. Laju perambatan pembakaran sebanding dengan peningkatan kecepatan aliran suplai oksigen (Aljarwi et al., 2020). Semakin luas area yang dilalui oleh oksigen maka kecepatan pembakaran akan semakin meningkat.

Hasil penelitian ini sejalan dengan penelitian-penelitian sebelumnya seperti yang telah dilakukan oleh (Lintang Pratama, Dwi Pangga, 2020), (Aljarwi et al., 2020) dan (Lalu Muhammad Alfian R, Sukainil Ahzan, 2020). Terlihat pada Tabel 2 dan Tabel 3 , ada kecenderungan bahwa briket dengan bahan dasar abu sekam padi menghasilkan kalor yang lebih tinggi dibandingkan dengan briket berbahan dasar abu sekam padi. Hal tersebut dapat terlihat dari perubahan suhu yang dihasilkan pada tiap-tiap pengukuran serta nilai kalor yang dihasilkan pada setiap perhitungan.

Terlihat juga bahwa baik rongga pada pelet-pelettabung berongga dan kotak berongga menyebabkan kalor yang dihasilkan lebih tinggi dibandingkan pada tabung pejal dan kotak pejal.

Namun dalam penelitian ini didapatkan hasil yang berbeda dari hasil penelitian (Asri \& Indrawati, 2018). Dalam penelitian ini cenderung kotak beronga menghasilkan kalor lebih tingggi dibandingkan dengan tabung pejal baik pada bahan dasar eceng gondok maupun bahan dasar abu sekam padi. Hal ini disebabkan karena dalam penelitian ini pembakaran dilakukan satu persatu, sehingga vaktor luas permukaan belum menunjukkan hasil perbedaan yang signifikan pada nilai kalornya.

Sedangkan pengaruh tekanan pada waktu pembentukan pelet (10 PSI, $20 \mathrm{PSI}$, dan 
$30 \mathrm{PSI}$ ), tampak jelas terlihat pada perubahan suhu dan nilai kalor yang dihasilkan. Baik pada briket berbahan dasar eceng gondok maupun briket berbahan dasar abu sekam padi, menunjukkan bahwa tekanan pembentukan briket paling efektif pada tekanan $20 \mathrm{PSI}$.

Tabel 2. Nilai Kalor yang dihasilkan pada briket Eceng Gondok dengan variasi Geometri dan tekanan

\begin{tabular}{|c|c|c|c|c|c|c|c|c|c|c|c|c|}
\hline \multirow{3}{*}{$\begin{array}{l}\text { Variabel } \\
\text { yang } \\
\text { diukur }\end{array}$} & \multicolumn{12}{|c|}{ Briket Eceng Gondong dengan Perekat Tepung Tapioka } \\
\hline & \multicolumn{3}{|c|}{ Kotak Pejal } & \multicolumn{3}{|c|}{ Kotak Berongga } & \multicolumn{3}{|c|}{ Tabung Pejal } & \multicolumn{3}{|c|}{ Tabung Berongga } \\
\hline & $\begin{array}{c}10 \\
\mathrm{PSI}\end{array}$ & $\begin{array}{l}20 \\
\text { PSI }\end{array}$ & $\begin{array}{c}30 \\
\text { PSI }\end{array}$ & $\begin{array}{c}10 \\
\text { PSI }\end{array}$ & $\begin{array}{l}20 \\
\text { PSI }\end{array}$ & $\begin{array}{c}30 \\
\text { PSI } \\
\end{array}$ & $\begin{array}{c}10 \\
\text { PSI }\end{array}$ & $\begin{array}{c}20 \\
\text { PSI } \\
\end{array}$ & $\begin{array}{c}30 \\
\mathrm{PSI}\end{array}$ & $\begin{array}{c}10 \\
\mathrm{PSI}\end{array}$ & $\begin{array}{c}20 \\
\mathrm{PSI}\end{array}$ & $\begin{array}{c}30 \\
\text { PSI }\end{array}$ \\
\hline T0 & 28.1 & 28.1 & 28.0 & 28.1 & 28.2 & 28.1 & 28.1 & 28.0 & 28.0 & 28.1 & 28.2 & 28.2 \\
\hline TA & 38.2 & 38.6 & 37.9 & 40.7 & 41.8 & 39.8 & 37.4 & 36.7 & 36.1 & 38.2 & 40.8 & 38.0 \\
\hline$\Delta \mathrm{T}$ & 10.1 & 10.5 & 9.9 & 12.6 & 13.6 & 11.7 & 9.3 & 8.7 & 8.1 & 10.1 & 12.6 & 9.8 \\
\hline Q (Joule) & $\begin{array}{c}9112 \\
.2\end{array}$ & 3.3 & $\begin{array}{c}8931 \\
.7 \\
\end{array}$ & $\begin{array}{c}11367 \\
7 \\
\end{array}$ & $\begin{array}{c}12269 \\
9\end{array}$ & $\begin{array}{c}10465 \\
5 \\
\end{array}$ & & $\begin{array}{c}7758 . \\
9\end{array}$ & $\begin{array}{c}7307 . \\
8\end{array}$ & $\begin{array}{l}911 \\
2.2\end{array}$ & $\begin{array}{c}1136 \\
7.7\end{array}$ & 931.7 \\
\hline
\end{tabular}

Tabel 3. Nilai Kalor yang dihasilkan pada briket sekam padi dengan variasi Geometri dan tekanan

\begin{tabular}{|c|c|c|c|c|c|c|c|c|c|c|c|c|}
\hline \multirow{3}{*}{$\begin{array}{c}\text { Variabel } \\
\text { yang diukur }\end{array}$} & \multicolumn{12}{|c|}{ Briket Abu Sekam dengan Perekat Tepung Tapioka } \\
\hline & \multicolumn{3}{|c|}{ Kotak Pejal } & \multicolumn{3}{|c|}{ Kotak Berongga } & \multicolumn{3}{|c|}{ Tabung Pejal } & \multicolumn{3}{|c|}{ Tabung Berongga } \\
\hline & $\begin{array}{c}10 \\
\text { PSI }\end{array}$ & $\begin{array}{c}20 \\
\text { PSI }\end{array}$ & $\begin{array}{c}30 \\
\text { PSI }\end{array}$ & $\begin{array}{c}10 \\
\text { PSI }\end{array}$ & $\begin{array}{c}20 \\
\text { PSI }\end{array}$ & $\begin{array}{c}30 \\
\mathrm{PSI}\end{array}$ & $\begin{array}{c}10 \\
\text { PSI }\end{array}$ & $\begin{array}{c}20 \\
\text { PSI }\end{array}$ & $\begin{array}{c}30 \\
\text { PSI }\end{array}$ & $\begin{array}{c}10 \\
\text { PSI }\end{array}$ & $\begin{array}{c}20 \\
\mathrm{PSI}\end{array}$ & $\begin{array}{c}30 \\
\text { PSI }\end{array}$ \\
\hline T0 & 27.6 & 27.4 & 27.2 & 27.2 & 27.6 & 27.4 & 27.4 & 27.2 & 27.4 & 27.6 & 27.4 & 27.8 \\
\hline TA & 39.4 & 40.8 & 41.2 & 41.6 & 42.6 & 43.2 & 36.0 & 36.8 & 37.8 & 38.2 & 39.4 & 40.0 \\
\hline$\Delta \mathrm{T}$ & 11.8 & 13.4 & 14.0 & 14.4 & 15.0 & 15.8 & 8.6 & 9.6 & 10.4 & 10.6 & 12.0 & 12.2 \\
\hline Q (Joule) & $\begin{array}{c}10646 \\
.9 \\
\end{array}$ & $\begin{array}{c}12090 . \\
6 \\
\end{array}$ & $\begin{array}{c}1263 \\
1.9 \\
\end{array}$ & $\begin{array}{c}12992 . \\
8\end{array}$ & $\begin{array}{c}13534 \\
2 \\
\end{array}$ & $\begin{array}{c}14256 . \\
0\end{array}$ & $\begin{array}{c}7759 . \\
6 \\
\end{array}$ & $\begin{array}{c}8661 . \\
9\end{array}$ & $\begin{array}{c}9383 . \\
7 \\
\end{array}$ & $\begin{array}{c}9564 . \\
2 \\
\end{array}$ & $\begin{array}{c}1082 \\
7.4 \\
\end{array}$ & $\begin{array}{c}1100 \\
7.8 \\
\end{array}$ \\
\hline
\end{tabular}

\section{SIMPULAN}

Dari hasil penelitian tersebut dapat disimpulkan bahwa: 1). Briket bahan dasar eceng gondok menghasilkan nilai kalor terbesar yakni 12269,9 Joule dengan geometri kotak berongga dan tekanan $20 \mathrm{PSI}, 2$ ). Briket bahan dasar abu sekam menghasilkan nilai kalor terbesar 14256,0Joule dengan geometri kotak berongga dan tekanan $30 \mathrm{PSI}$.

\section{UCAPAN TERIMAKASIH}

Ucapan terimakasih peneliti sampaikan kepada LPPM Undikma Mataram yang telah mendanai penelitian ini. Ucapan terimakasih juga kami sampaikan kepada pihak laboratorium Fisika dan Laboratorium Kimia Undikma, serta mahasiswa yang telah terlibat dan membantu dalam pengumpulan data pada penelitian ini.

\section{DAFTAR RUJUKAN}

Aljarwi, M. A., Pangga, D., \& Ahzan, S. (2020). Uji Laju Pembakaran Dan Nilai Kalor Briket Wafer Sekam Padi Dengan Variasi Tekanan. ORBITA: Jurnal Kajian, Inovasi Dan Aplikasi Pendidikan Fisika, 6(2), 200. https://doi.org/10.31764 /orbita. v6i2. 2645
Ariyanto, E., Karim, M. A., \& Firmansyah, A. (2014). Biobriket Enceng Gondok (Eichhornia Crassipes) Sebagai Bahan Bakar Energi Terbarukan. Reaktor, 15(1), 59. https://doi.org/10.14710/reaktor.15. 1.59-63

Asri, S., \& Indrawati, R. T. (2018). Pengaruh Bentuk Briket Terhadap Efektivitas Laju Pembakaran. Jurnal Penelitian Dan Pengabdian Kepada Masyarakat UNSIQ, 5(3), $\quad 338-341$. https://doi.org/10.32699/ppkm.v5i3.481

Jamilatun, S. (2012). Sifat-Sifat Penyalaan dan Pembakaran Briket Biomassa, Briket Batubara dan Arang Kayu. Jurnal Rekayasa Proses, 2(2), 37-40. https://doi.org/10.22146/jrekpros.554

Lalu Muhammad Alfian R, Sukainil Ahzan, D. S. B. (2020). The Effect of the Type and Composition of the Adhesive on the Physical Properties and the Rate of Combustion Hyacinth Biobriquettes No Title. Lensa Kependidikan Fisika, 8(2), 85-92.

Lintang Pratama, Dwi Pangga, D. S. B. P. (2020). Quality Analysis of Briquettes based on Waterding with Variation of Pressure and Pellet Geometry to Water 
Content and Value of Calories. Lensa Kependidikan Fisika, 8(2), 55-62.

Nurlela. (2015). Briket BatuBara dengan Penyulut Enceng Gondok dengan Perekat Tapioka. Media Teknik, 12, 18.

Pangga, D., \& Ahzan, S. (2019). Pengembangan Eceng Gondok sebagai Bahan Dasar Pembuatan Briket Sumber Energi Alternatif. 24-25.

Patabang, D. (2012). Karakteristik Termal Briket Arang Sekam Padi Dengan Variasi Bahan Perekat. Jurnal Mekanikal, 3(2), 286-292.

Sulistyaningkarti, L., \& Utami, B. (2017). Making Charcoal Briquettes from Corncobs Organic Waste Using Variation of Type and Percentage of Adhesives. JKPK (Jurnal Kimia Dan Pendidikan Kimia), 2(1),

43. https://doi.org/10.20961/jkpk.v2i1.8518

Supatata, N., Buates, J., \& Hariyanont, P. (2013). Characterization of Fuel Briquettes Made from Sewage Sludge Mixed with Water Hyacinth and Sewage Sludge Mixed with Sedge. International Journal of Environmental Science and Development, April 2013, 179-181. https://doi.org/10.7763/ijesd.2013.v4.330 